\title{
Application of Linear Programming Model to Refugee Migrating Problem
}

\author{
Chongyu Jiang, Xiaorong Li, Yandong Li \\ School of Information, Beijing Wuzi University, Beijing, China \\ Email: chongyu_jiang@live.com
}

Received 12 April 2016; accepted 28 May 2016; published 31 May 2016

Copyright (C) 2016 by authors and Scientific Research Publishing Inc.

This work is licensed under the Creative Commons Attribution International License (CC BY). http://creativecommons.org/licenses/by/4.0/

\begin{abstract}
The refugee immigration problem can be considered as a special "transportation problem". Linear Programming Model is built, where two objectives with weight in the objective function, for the shortest routes that the refugees go along and the minimum number of refugees stayed in each country. An example of EU is introduced and calculated on Lingo software. The results show that the model is available to solve the refugee immigration problem in different scale.
\end{abstract}

\section{Keywords}

Refugee, Linear Programming Model, Optimal Solution

\section{Introduction}

In recent years, the tribal, ethnic and religious conflicts are continuous in the West Asia and North Africa. These conflicts bring about substantial refugees who have to migrate to other countries. According to the report of the United Nations High Commissioner for Refugees (UNHCR), the number of refugees reached about 59 million all over the world, and reached the highest after World War II [1]. In 2014, the number of displaced people has increased by 8.3 million over the previous year. The latest data of UNHCR show that about 380 thousand refugees have arrived in Europe, which has surpassed the total of last year [1]. Mediterranean locates among Europe, Africa and the Asian continent, so it is the essential channel for refugees to reach Italy, Greece and Spain through the Mediterranean. Due to the proximate geography relationship between Europe and the Middle East, more and more Middle East refugees cross the Mediterranean by boat to reach Europe. According to the date of the international organization for migration (IOM), about $70 \%$ of the refugees crossed Mediterranean to reach Greece, about $28 \%$ to reach Italy [2]. After the refugee arrived in continental Europe, they traveled to Germany, Sweden, France and the UK such rich European countries. Since 2014, about ten thousand Middle East refugees continue to enter European countries, the refugee problem gradually enter the vision of 
European governments and the United Nations. In 2015, about 1.08 million refugees applied for asylum in Europe, Germany received 420 thousand asylum applications which were the most. Sweden is the country with the most asylum applications according to the proportion of population, every 1000 Swedish will take nearly 8 asylum applications [3].

To abstract and solve the problem, mathematic model should be build based on the information of the refugee problem shown above. Due to this, the flow network of refugees is studied and shown in Figure 1.

From the topology of the problem, the refugees migrating can be considered as a special transportation problem. The refugees' origin countries can be seen as the "origin" in the transshipment problem, and the asylum countries are considered as "marketing". The transportation problem which was firstly studied by Hitchcock F. L. in 1941 [4] had been concerned many years. A method for solving the minimum cost transportation problem with time limited was provided by Li et al. [5] [6]. Zeng [7] made the demand, delivery price and supply quantity as interregional number for the uncertainty. Han [8] transferred the transportation problem to a kind of linear integer programming and proved it theoretically. Hu [9] introduced and modeled satisfaction optimization transportation problem in order to maximize the relative equalities among the members. $\mathrm{Wu}$ [10] discussed the multi-objective fuzzy transportation problem with three types of transshipment. Rani [11] proposed a method to solve the fully fuzzy unbalanced transportation problem in which the total availability production was more than the total demand. Aizemberg [12] proposed a column generation-based heuristic to find good feasible solutions of a crude oil transportation problem by tankers. Zhenping Li [14] studied the problem of how to arrange the transportation plan in order to minimize the total cost when the total volume of supply was insufficient. However, the refugees migrating is different from the traditional transportation problem for its multiple transshipment, so we aim to build a model that can roughly arrange the refugees in Middle Eastern safety and effectively to the most extent.

In this paper, the refugees migrating problem is studied. A mathematical model to minimize the mortality and the spending time of the refugee on the way is established, and relational simulation is done on an example. The remainder of this paper is organized as follows. Section 2 discusses factors influencing refugee flows. Section 3 describes the problem and formulates it into a mathematical model. The simulation on an example is given in Section 5 . Section 5 contains the conclusions of this work.

\section{Factors Influencing Refugee Flows}

Refugee flow is influenced by many factors. They need a relatively safe place, so the Europe becomes an ideal choice because of their steady political situation. And European countries are not allowed to accept admissions of refugees without planning. The number of refugee percentage of the population is used to measure refugee crisis by many countries. Therefore, the entry of refugees will exist certain restrictions according to their own national conditions. However, not all asylum applications will be approved successfully. For European countries, refugees will occupy the food, health care, housing and other resources. It means that the part of the tax will be consumed. With concerns of culture and safety, the inhabitants of the country will affect the refugee policy

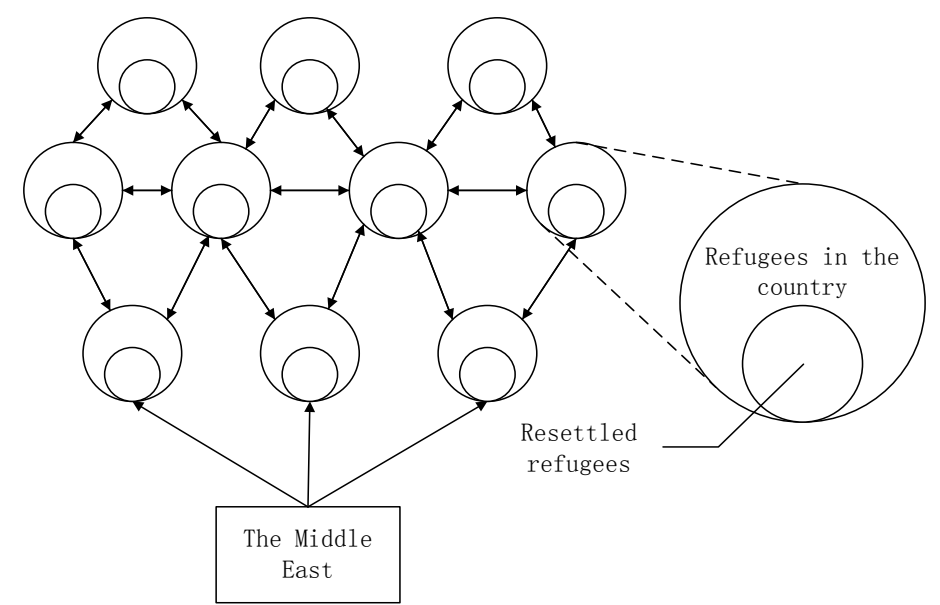

Figure 1. Refugee flow network. 
[13]. As a result, the European countries will make a compromise settlement plan to limit the number of asylum seekers. At the same time, the refugees in the process of wandering in the absence of safety and health protection, thus the probability of death will be relatively high, which will affect the number of dynamic refugees. In addition, the means of transportation and walking distance are important factors. In the absence of other organizations' assistance, the refugees are allowed to choose walk only and cannot take the plane or direct train went to non-neighbors. The helpless refugees tend to choose the nearest country as next destination. Therefore, whether the national border and distance should be considered as a parameter.

\section{The Multiple-Goal Linear Programming Model of Refugee Problem}

\subsection{Problem Description}

As is shown in Figure 1, the refugees migrating can be considered as the linear programming, namely a special transportation problem. The refugees' origin countries can be seen as the “origin” in the transshipment problem, and the asylum countries are considered as "marketing”.

In this process we mainly consider the mortality of refugees on the way and the maximum refugees that the asylum countries can accept. Our goal is to decrease the mortality and the spending time of the refugee on the way. In addition, we lead into the reachable matrix to express whether the two countries are on the border. If it is yes, “ 1 ” indicates in the table, otherwise, “ 0 ” indicated.

Before presenting the mathematical model, some necessary assumptions should be defined.

\subsection{Assumptions and Symbols}

\subsubsection{Assumptions}

Before presenting the mathematical model, some necessary assumptions should be defined.

- All refugees start from the Middle East.

- Refugees immigrants in European countries need to submit an application, if the application is approved successfully, then they have the right to stay in the country. On the contrary, if the application is not approved successfully, the refugees have no choice but leave for the next neighboring countries until get an approved application.

- $\quad$ The number of refugee in every period of a year is equal.

- A year is divided into twelve periods. In every period, the refugees just migrate from one country to another, and they only have one chance to migrate to another country.

- $\quad$ Once the refugee reach to the Europe, they have to take the way on land to migrate.

\subsubsection{Symbols}

Before presenting the mathematical model, the following set of indices and parameters are defined.

$G(V, S)$ : directed graph where $V=\left\{v_{1}, v_{2}, \cdots, v_{n}\right\}$ the set of country nodes and $S$ is the set of arcs;

$t$ : set of time periods or months in a planning horizon or a year $(t=0,1,2, \cdots, T)$;

$d_{i j}$ : distance from country $i$ to $j$, and $d_{i j} \in D$;

$a_{i j}$ : access from country $i$ to $j$, equals to 1 when routes to country nodes $j$ from $i$ are available, 0 otherwise;

$r_{i j}$ : rate of death for refugees move from country node $i$ to $j$;

$U$ : the total number of the refugees from the Middle East in a planning horizon or a year, where $U_{t}$ is the total number of the refugees in time period $t$;

$Q_{i}$ : maximum number of the refugees can be allowed to cross the border of country $i$;

$p_{i}$ : maximum number of the refugees whose asylum requests granted by country nodes $i$ per time period or month;

$\alpha_{i}$ : resources coefficient of each country;

$\beta$ : policy coefficient of each country.

The variables that need to be determined are as follows:

$y_{i t}$ : the number of the refugees whose asylum requests granted by country $i$ in time period or month $t$.

$Y_{i t}$ : the number of the refugees crossing the border of country $i$;

$x_{i j t}^{1}$ : the number of the refugees departing country $i$ to $j$;

$x_{i j t}^{2}$ : the number of the refugees arriving country $j$ from $i$. 


\subsection{The Multiple-Goal Linear Programming Model}

The multiple-goal linear programming model is presented below:

$$
\begin{aligned}
& \min \sum_{i \in V} \sum_{j \in V \cap j} \sum_{j \neq i} d_{i j \in T \cap t \neq 0} \frac{\left(x_{i j t}^{1}+x_{i j t}^{2}\right)}{2} \\
& \min \sum_{i \in V} \sum_{j \in V \cap j \neq i} \sum_{j \in T \cap t \neq 1}\left(x_{i j t}^{1}-x_{i j t}^{2}\right) .
\end{aligned}
$$

Subject to:

$$
\begin{gathered}
x_{i j 0}^{1}=0 \\
\sum_{j \in V \cap j \neq i} x_{1 j t}^{1}=U_{t} \\
x_{i j t}^{2}=\left(1-r_{i j t}\right) x_{i j t}^{1} \\
\sum_{j \in V \cap j \neq i} x_{i j t}^{1}=Y_{i, t-1}-y_{i, t-1} \\
x_{i j t}^{1} \leq a_{i j} M \\
\sum_{i \in V \cap i \neq j} x_{i j t}^{2}=Y_{j t} \\
\sum_{i \in V} Y_{i k} \leq \sum_{t=1}^{k} U_{t} \\
0 \leq Y_{i t} \leq \alpha_{i} Q_{i} \\
0 \leq y_{i t} \leq \alpha_{i} \beta_{i} p_{i} \\
\sum_{t \in T} U_{t}=U \\
d_{i j} \geq 0,0 \leq r_{i j} \leq 1, x_{i j t}^{1} \geq 0, x_{i j t}^{2} \geq 0, U_{t} \geq 0 .
\end{gathered}
$$

The objective function (1) is to minimize the travel time, (2) is to minimize the number of death among all the refugees. Constraints (3) are the variable initialization. Constraints (4) ensues that all the refugees in the Middle East depart successfully. Constraints (5) determine the death in the flows of refugees. Constraints (6) (7) and (8) impose the refugees whose asylum requests are not be approved, and have to leave the current country to another available country. Constraints (9) restrict the total number of the refugees in Europe, and the number of the refugees crossing in current country, and refugees resettled are limited by Constraints (10) and (11). Constraints (12) define the scale of the refugees and constraints (13) ensure the range of parameters and variables.

In the linear programming model, every route has the same rate of death in the constraints, and refugees are assumed only can travel between countries by land transportation. In our paper, we use the adjacent matrix to limit the access of two country nodes.

To solve the problem facially, the two objective functions are combined as:

$$
\min \omega_{1} \sum_{i \in V} \sum_{j \in V \cap} \sum_{j \neq i} d_{i j \in T \cap t \neq 0} \frac{\left(x_{i j t}^{1}+x_{i j t}^{2}\right)}{2}+\omega_{2} \sum_{i \in V} \sum_{j \in V \cap j} \sum_{j \neq i}\left(x_{i j \in T}^{1}-x_{i j t}^{2}\right) .
$$

The coefficient $\omega_{1}$ and $\omega_{2}$ represent the importance of efficiency and safety of the flows.

\section{Results and Discussion}

\subsection{Source of Data}

To test the model and solve the problem, an example with actual data of Europe refugee crisis is needed. 
In Figure 2, we can see EU minister voted by a majority to relocate refugees UN-wide in September 2015. We estimate the number of migrants EU member states are being asked to take, and we assume that the number of refugee in each month is equal. So we use the number multiplied by twelve and got the number of the EU countries in 2015. Beside this, we also have to adjust some of the number. For example, UK has opted out, Ireland has offered to take 4000, Denmark will take 1000, and Switzerland and Norway have also agreed to take refugee, number yet to be agreed.

Figure 3 shows that some part of countries accepted asylum applications per 100,000 local population in 2015. The massive refugees each country plan to accept is through combined the information in the two above pictures. There are eight countries (Norway, Switzerland, Denmark, Italy, Iceland, Greece, Ireland, United Kingdom) accepted asylum applications but the EU minister did not relocate refugees for different reasons, these countries are assumed that they can accepted the refugees who submitted the asylum applications. There are also eight countries (Croatia, Slovakia, Slovenia, Spain, Czech Republic, Poland, Romania, Portugal) did not accept the asylum applications in 2015, but the EU minister relocate refugees in there. We consider these countries accept the refugees and we assume the refugees will does not mind. After the above date statistics, the maximum capacity of the European countries is shown in Table 1 although some of these are not EU countries.

There are six routes will be selected by the refugees. Three of these routes pass the Mediterranean. They are western Mediterranean, central Mediterranean and eastern Mediterranean. However, each route has different levels of safety and accessibility, with the most popular route being Eastern Mediterranean, and the most dangerous is Central Mediterranean. According to the statistical date by IOM (International Organization for Migration), the mortality of the routes cross Mediterranean is shown in Table 2.

Besides, three road routes are from the western Balkan Mountains, the eastern boundary of Albania, and finally reach to Greece. We use the normal mortality instead the death on land routes. In addition, after the refugees arrived in Europe, the mortality is not considered particularly, because there is no clearly difference in Europe unlike crossing the Mediterranean, so we set a confirm mortality on the Europe land in our model.

We measure the straight line distance between the capital of any two countries in the Europe from the map, and the distance is regarded as the distance which the refugees may go through. The distance is the base on the model's objective function.

Migrants from Italy $\quad$ Migrants from Greece

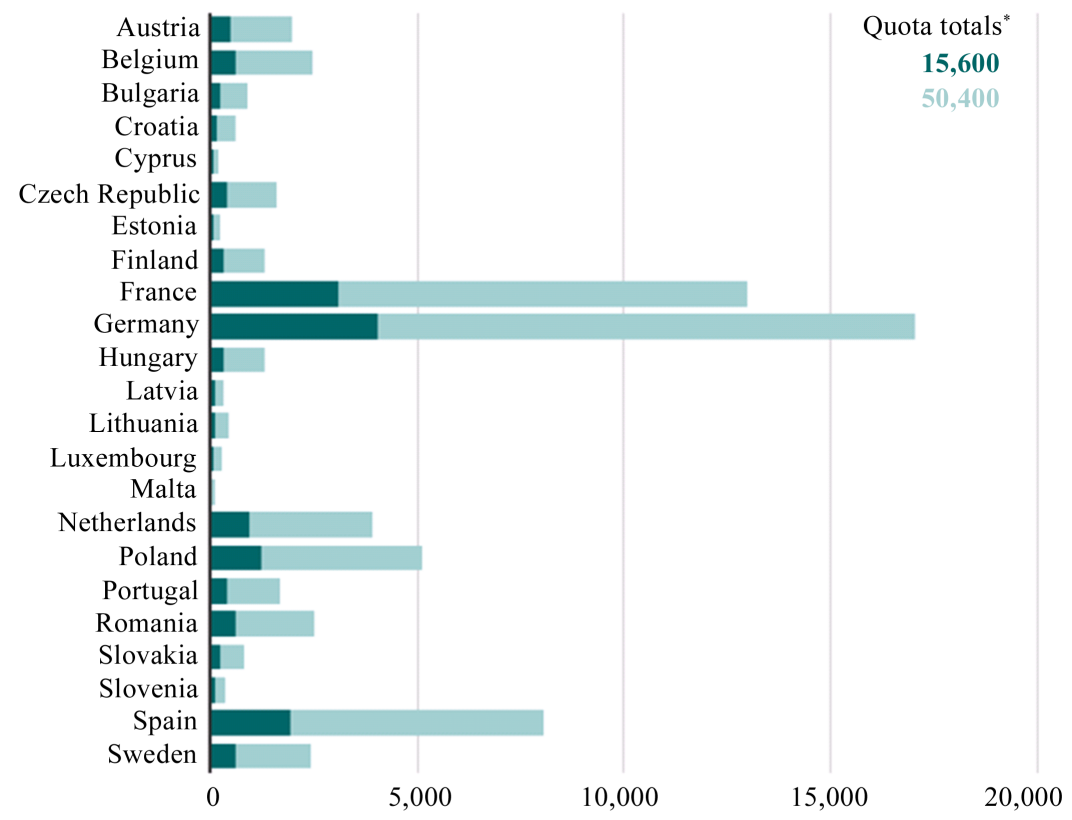

Note: UK has opted out, Ireland has offered to take 4,000, Denmark will take 1,000

Switzerland and Norway have also agreed to take refugees, numbers yet to be agreed.

"Relocation of a further 54,000 migrants still to be decided.

Figure 2. Number of migrant EU member states are being asked to take [3]. 
Table 1. The maximum capacity of the European countries [1].

\begin{tabular}{cccc}
\hline Country & Capacity & Country & Capacity \\
\hline Sweden & 28800 & Italy & 6800 \\
Hungary & 26400 & Iceland & 3840 \\
Austria & 27600 & Greece & 8000 \\
Norway & 31200 & France & 156000 \\
Finland & 26400 & Ireland & 48000 \\
Germany & 204000 & United Kingdom & 27600 \\
Switzerland & 30000 & Croatia & 9600 \\
Belgium & 30000 & Slovakia & 9600 \\
Denmark & 12000 & Slovenia & 6000 \\
Malta & 1200 & Spain & 96000 \\
Luxembourg & 2400 & Czech Republic & 21600 \\
Netherlands & 50400 & Poland & 62400 \\
Bulgaria & 12000 & Romania & 30000 \\
Cyprus & 6000 & Portugal & 24000 \\
Total & 997840 & & \\
& & &
\end{tabular}

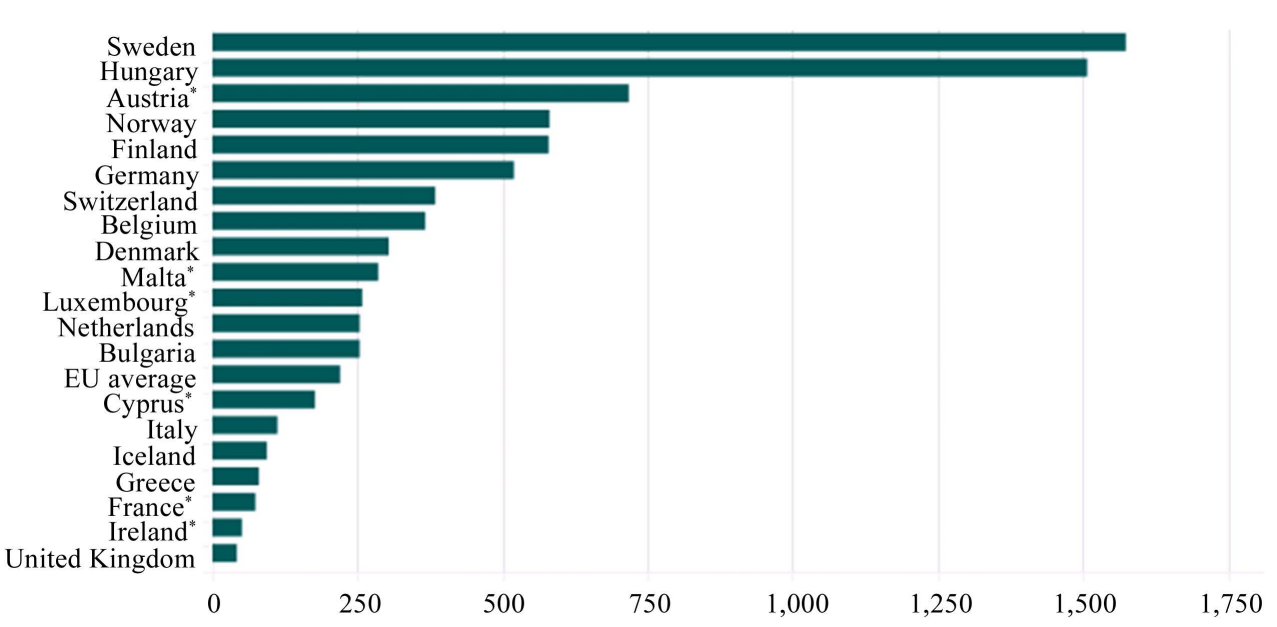

Figure 3. Asylum applications per 100,000 local people population 2015 [3].

\subsection{Simulation Results}

Clearly, the model is a linear Programming problem with 20,996 variables and 22,496 constraints because of the set of time periods or months in a planning horizon or a year. Lots of polynomial algorithms were introduced to solve the problem, such as simplex method and interior point methods. Nevertheless, due to the huge number of variables and constraints, we compile a program by LINGO to solve.

The problem solution could be obtained by LINGO within 20 seconds, and the result of analogue computation is shown in Table 3 and Figure 4. The amount of the refugees could be got from Table 3, and the route of refugees' movement could be seen in Figure 4.

\subsection{Discussion}

Influx Refugees might be increased by the continuing war of origin countries. More than 942,000 crossed into Europe in 2015 while 570,000 migrants applied for asylum in 2014 because of the crisis of Syria. 
Table 2. The mortality of three routes in 2015 [2].

\begin{tabular}{ccccc}
\hline $\begin{array}{c}\text { Mediterranean } \\
\text { route }\end{array}$ & Summery & Arrival & Death & Mortality \\
\hline Western & 3945 & 3845 & 100 & 0.025348542 \\
Central & 153,206 & 150,317 & 2889 & 0.018856964 \\
Eastern & 802,625 & 801,919 & 706 & 0.000879614 \\
\hline
\end{tabular}

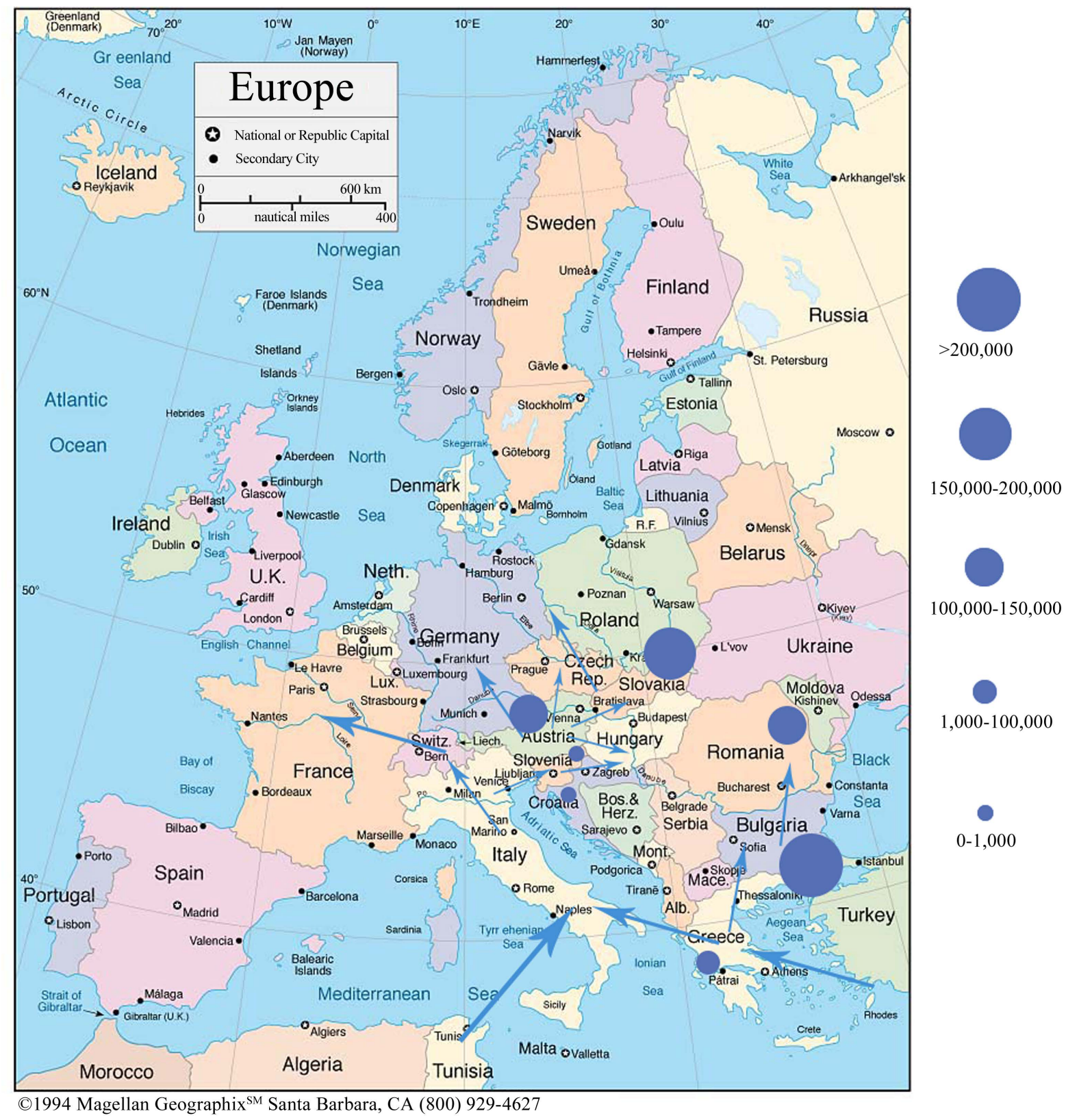

Figure 4. Result of analogue computation.

In addition to discuss the influence of crisis expanding, the total number of refugees is augmented by a factor of 10. However, the solution is infeasible for the large scale. In order to clear the traffic, the capacities $Q_{i t}$ should be also increased by policy which need the contribution of the UN or UE and the effort of government of 
Table 3. Result of analogue computation.

\begin{tabular}{|c|c|c|c|c|}
\hline Country & $\begin{array}{l}\text { Current number of } \\
\text { refugees }\end{array}$ & $\begin{array}{l}\text { Cumulative number of } \\
\text { refugees resettled }\end{array}$ & Population [6] & $\begin{array}{l}\text { Current number of } \\
\text { refugees/population }\end{array}$ \\
\hline Sweden & 0 & 0 & $9,141,187$ & $0.0000 \%$ \\
\hline Hungary & 0 & 11,264 & $9,832,087$ & $0.0000 \%$ \\
\hline Austria & 143,863 & 14,720 & $8,671,043$ & $1.6320 \%$ \\
\hline Norway & 0 & 0 & $5,192,976$ & $0.0000 \%$ \\
\hline Finland & 0 & 0 & $5,490,913$ & $0.0000 \%$ \\
\hline Germany & 0 & 21,760 & $81,132,173$ & $0.0000 \%$ \\
\hline Switzerland & 0 & 11,200 & $7,695,720$ & $0.0000 \%$ \\
\hline Belgium & 0 & 0 & $11,270,107$ & $0.0000 \%$ \\
\hline Denmark & 0 & 0 & $5,662,123$ & $0.0000 \%$ \\
\hline Malta & 0 & 448 & 431,250 & $0.0000 \%$ \\
\hline Luxembourg & 0 & 0 & 568,863 & $0.0000 \%$ \\
\hline Netherlands & 0 & 0 & $16,904,745$ & $0.0000 \%$ \\
\hline Bulgaria & 208,217 & 7040 & $7,180,594$ & $2.8180 \%$ \\
\hline Cyprus & 0 & 3200 & $1,165,194$ & $0.0000 \%$ \\
\hline Italy & 0 & 9856 & $1,174,423$ & $0.0000 \%$ \\
\hline Iceland & 0 & 0 & 331,520 & $0.0000 \%$ \\
\hline Greece & 78,429 & 61,440 & $10,891,993$ & $0.7149 \%$ \\
\hline France & 0 & 33,280 & $64,677,753$ & $0.0000 \%$ \\
\hline Ireland & 0 & 0 & $4,626,557$ & $0.0000 \%$ \\
\hline United Kingdom & 0 & 0 & $64,897,438$ & $0.0000 \%$ \\
\hline Croatia & 512 & 5120 & $4,330,573$ & $0.0118 \%$ \\
\hline Slovakia & 168,261 & 4608 & $5,422,908$ & $3.0094 \%$ \\
\hline Slovenia & 320 & 3200 & $2,049,080$ & $0.0156 \%$ \\
\hline Spain & 0 & 0 & $47,263,733$ & $0.0000 \%$ \\
\hline Czech Republic & 0 & 6912 & $10,480,761$ & $0.0000 \%$ \\
\hline Poland & 0 & 0 & $38,477,597$ & $0.0000 \%$ \\
\hline Romania & 141,264 & 16,000 & $19,956,065$ & $0.7029 \%$ \\
\hline Portugal & 0 & 0 & $10,568,339$ & $0.0000 \%$ \\
\hline Total & 740,866 & 210,048 & & \\
\hline
\end{tabular}

Table 4. Result of analogue computation a larger scale.

\begin{tabular}{cccc}
\hline Country & $\begin{array}{c}\text { Current number of } \\
\text { refugees }\end{array}$ & $\begin{array}{c}\text { Cumulative number of } \\
\text { refugees resettled }\end{array}$ & $\begin{array}{c}\text { Population [6] } \\
\text { refugees/population }\end{array}$ \\
Sweden & 0 & 7680 & $9,141,187$ \\
Hungary & 1408 & 15,488 & $9,832,087$ \\
\hline
\end{tabular}




\section{Continued}

\begin{tabular}{|c|c|c|c|c|}
\hline Austria & 961,568 & 16,192 & $8,671,043$ & $9.9824 \%$ \\
\hline Norway & 0 & 8320 & $5,192,976$ & $0.0000 \%$ \\
\hline Finland & 0 & 0 & $5,490,913$ & $0.0000 \%$ \\
\hline Germany & 0 & 87,040 & $81,132,173$ & $0.0000 \%$ \\
\hline Switzerland & 1600 & 17,600 & $7,695,720$ & $0.0208 \%$ \\
\hline Belgium & $2,246,771$ & 16,000 & $11,270,107$ & $16.6220 \%$ \\
\hline Denmark & 0 & 4480 & $5,662,123$ & $0.0000 \%$ \\
\hline Malta & 64 & 704 & 431,250 & $0.0148 \%$ \\
\hline Luxembourg & 128 & 1280 & 568,863 & $0.0225 \%$ \\
\hline Netherlands & 2,101,903 & 26,880 & $1,6904,745$ & $11.0588 \%$ \\
\hline Bulgaria & 862,874 & 7040 & $7,180,594$ & $10.7276 \%$ \\
\hline Cyprus & 320 & 3520 & $1,165,194$ & $0.0275 \%$ \\
\hline Italy & 131,500 & 10,752 & $1,174,423$ & $10.0695 \%$ \\
\hline Iceland & 0 & 0 & 331,520 & $0.0000 \%$ \\
\hline Greece & 570,000 & 61,440 & $10,891,993$ & $4.9730 \%$ \\
\hline France & 23,770 & 91,520 & $64,677,753$ & $0.0367 \%$ \\
\hline Ireland & 0 & 17,920 & $4,626,557$ & $0.0000 \%$ \\
\hline United Kingdom & 1472 & 14,720 & $64,897,438$ & $0.0023 \%$ \\
\hline Croatia & 96,000 & 5632 & $4,330,573$ & $2.1687 \%$ \\
\hline Slovakia & 960,000 & 5120 & $5,422,908$ & $15.0402 \%$ \\
\hline Slovenia & 224,405 & 3520 & $2,049,080$ & $9.8705 \%$ \\
\hline Spain & 78,348 & 61,440 & $47,263,733$ & $0.1655 \%$ \\
\hline Czech Republic & 1152 & 11,520 & $10,480,761$ & $0.0110 \%$ \\
\hline Poland & 0 & 16,640 & $38,477,597$ & $0.0000 \%$ \\
\hline Romania & 300,000 & 16,000 & $19,956,065$ & $1.4810 \%$ \\
\hline Portugal & 180,000 & 14,080 & $10,568,339$ & $1.6747 \%$ \\
\hline Total & $8,743,283$ & 542,528 & & \\
\hline
\end{tabular}

each country. Then $Q_{i t}$ is increased ten times so that the results (Table 4 and Figure 5) can be obtained.

Result in Table 4 shows that more refugees cross into the Europe and lead a vagrant life while only $6.2 \%$ are resettled. Meanwhile, Slovakia, Slovenia, Italy, Bulgaria, Netherlands, Belgium, Austria, Greece, Portugal and Romania occur serious refugee crisis. Time to resettle the refugees would be prolonged largely which might cause more death and insecurity like crime and riot. Therefore, facing this problem, countries should add the asylum scheme or seek help for countries of other continent as more as possible.

\section{Conclusion}

The refugee immigration problem can be considered as a special "transportation problem”. Linear Programming Model is built, where two objectives with weight in the objective function, for the routes that the refugees go along and number of refugees stayed in each country. An example of EU is introduced and calculated on Lingo 


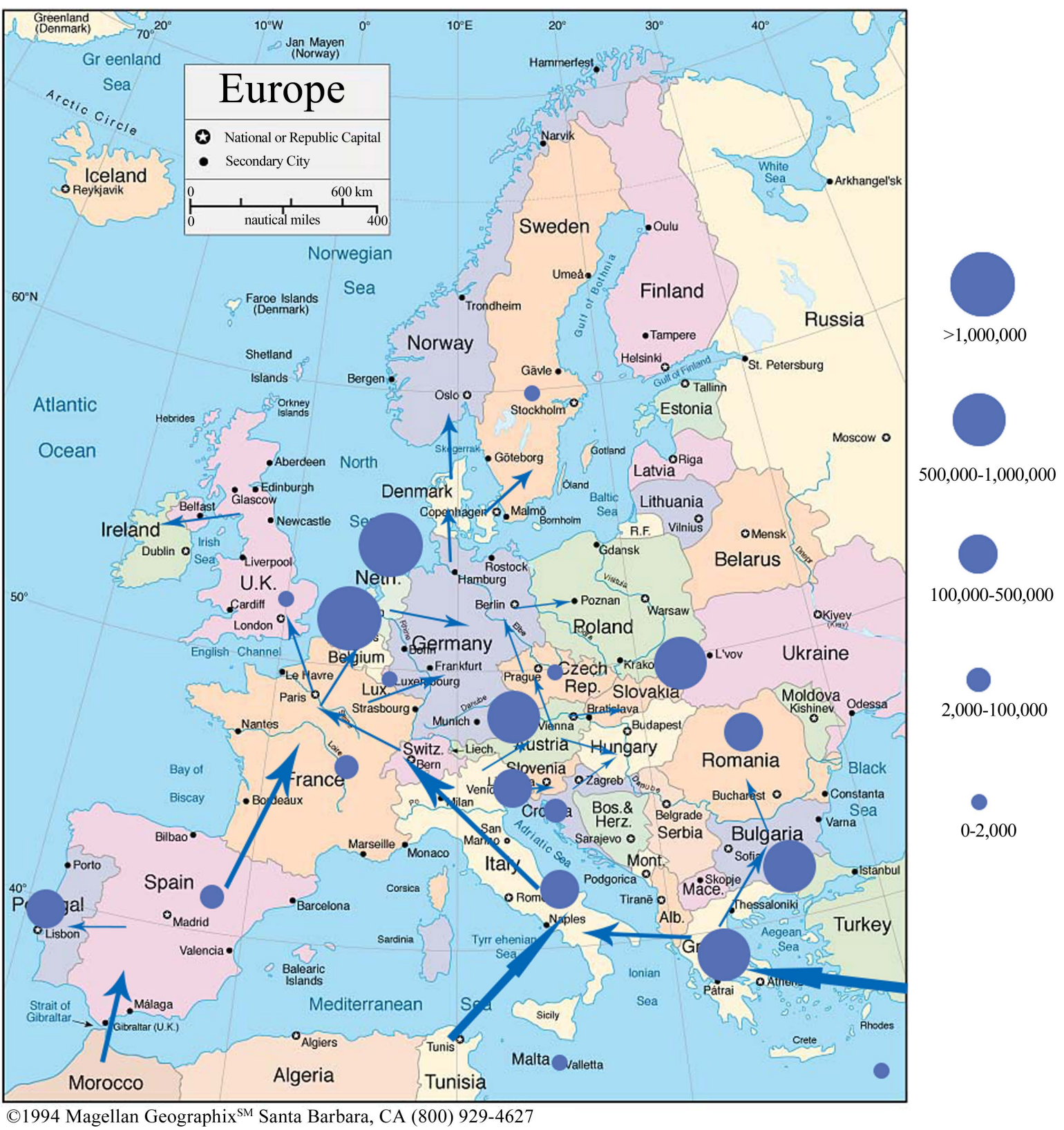

Figure 5. Result of analogue computation a larger scale.

software. The results show that the model is available to solve the refugee immigration problem in different scale.

\section{References}

[1] The UN Refugee Agency (2014) Statistical Yearbook: Table of Contents for the Excel Annex Tables.

[2] International Organization for Migration. Mediterranean Update: Migration Flows Europe: Arrivals and Fatalities. http://www.iom.int/

[3] BBC Europe. Migrant Crisis: Migration to Europe Explained in Seven Charts. http://www.bbc.com/news/world-europe-34131911

[4] Hitchcock, F.L. (1941) The Distribution of a Product from Several Sources to Numerous Locations. Journal of Mathematics and Physics, 20, 224-230. http://dx.doi.org/10.1002/sapm1941201224 
[5] Li, Z. (2001) The Transportation Problem of the Shortest Time Limit and Its Algorithm. Chinese Journal of Management Science, 9, 50-56.

[6] Li, Z., Xu, Q., Li, N. and Ma, Y. (2011) A Method for Solving the Minimum Cost Transportation Problem with Time Limited. Operations Research and Management Science, 20, 9-14.

[7] Zeng, J., Zhang, X., and Ye, J. (2008) An Interval Programming Model and Algorithm for Transportation Problem. Journal of Sichuan University of Science \& Engineering (Natural Science Edition), 21, 30-32.

[8] Han, W. and Zhang, Q. (2008) Linear Integer Programming Model on Transportation Problem. Operations Research and Management Science, 17, 12-15.

[9] Hu, X. and Li, D. (2014) Satisfaction Optimization Transportation Problem. Operations Research Transactions, 18, 36-44.

[10] Wu, Z. (2013) Research on Two Types of the Fuzzy Transportation Problems. MS Thesis, Guangzhou University, Guangzhou.

[11] Rani, D., Gulati, T.R. and Kumar, A. (2014) A Method for Unbalanced Transportation Problems in Fuzzy Environment. Indian Academy of Sciences, 39, 573-581.

[12] Aizemberg, L., Kramer, H., Pessoa, A. and Uchoa, E. (2014) Formulations for a Problem of Petroleum Transportation. European Journal of Operational Research, 237, 82-90.

[13] Schmeidl, S. (2001) Conflict and Forced Migration: A Quantitative Review, 1964-1995. In: Zolberg, A. and Benda, P., Eds., Global Migrants, Global Refugees_-Problems and Solutions, Bergham Books, New York, USA.

[14] Li, Z.P. and Jiang, C.Y. (2016) Study on the Transportation Problem of Petrol Secondary Distribution with Considering Shortage Cost. Open Journal of Modelling and Simulation, 4, 34-40. http://dx.doi.org/10.4236/ojmsi.2016.42004 